\title{
Nomear é trazer à existência: a onomástica (de crianças e de bichos) e os apelidos na produção da pessoa Capuxu
}

Emilene Leite de Sousa A PRESENTA ÇÃ O

(UFMA)

Esta reflexão onomástica constituiu parte de minha pesquisa sobre a produção da pessoa Capuxu à luz da análise dos corpos das crianças. E sobre como, através de fortes investimentos feitos no corpo da criança e de demais aspectos - como o sistema endogâmico com união preferencial entre primos e o sistema de apadrinhamento - o sistema de nominação fundava a pessoa Capuxu e, de forma mais ampla, a própria identidade do povo.

O povo Capuxu é um grupo camponês endogâmico que habita o Sítio SantanaQueimadas no sertão da Paraíba. Este povo vive basicamente da agricultura de subsistência e construiu uma identidade coletiva reconhecida por todos os habitantes das redondezas. Ele se autodenomina e é denominado como povo Capuxu, fazendo alusão a uma espécie de abelha de tipo capuxu que teria sido objeto de caça de um de seus antepassados, João Capuxu, tendo se tornado o apelido Capuxu o etnônimo do povo.

A comunidade consta de quase duzentos habitantes e praticamente quatro sobrenomes: Ferreira, Menezes, Lima e Costa. Além disso, foi caracterizada em sua origem por um modo de nomear endonímico, com transmissão de nomes, passando com o tempo a se tornar exonímico. Neste artigo analisarei o processo através do qual o sistema endonímico tornou-se exonímico e como, para além da onomástica, os apelidos e a atribuição dos nomes aos bichos fazem parte da constituição da pessoa Capuxu.

O sistema de nominação, vinculado ao sistema de parentesco, é um importante indicador da fabricação da pessoa'. Por isso, ele representou importante foco de análise desta pesquisa, cujo objetivo era a analisar a produção da pessoa Capuxu.

Entre os Capuxu podemos dizer que o ato de nomear as crianças é um importante momento na produção da pessoa. Além de se constituir num signo de identidade, a nomeação revela formas de identificação, interação e distinção entre 
É o nome que designa a pessoa, afinal, evocar o nome é evocar a pessoa. Por isso, entre os Capuxu, antes de nascer as crianças já possuem um nome através do qual serão reconhecidas. Atribuir um nome ao feto ainda no ventre é uma maneira de transformá-lo, antes mesmo de ser conhecido, em pessoa. É atribuir-Ihe um dos primeiros atributos reconhecidos como da pessoa².

Estudar a onomástica Capuxu é como fazer uma espécie de escatologia individual, embora seu germe seja social e tudo desemboque em relações sociais. Por isso o nome, que é parte constituinte e fundamental da pessoa, ao mesmo tempo revela as profundezas da vida social. O nome é como uma espécie de ponte que liga a pessoa ao grupo, a parte ao todo. Assim, a onomástica Capuxu revela, de certa forma, um pertencimento a uma identidade e a um grupo social.

Com base nesta percepção passei a eleger perguntas que me norteassem no complexo labirinto das nomeações das crianças Capuxu: Ora, de que modo o nome faz a pessoa? Qual a função do sistema de nominação? Quais as formas de nomear nesse grupo camponês? E quem detém o poder nomear? Como se deu a transformação do sistema onomástico Capuxu? Teria este sistema endonímico se transformado num sistema exonímico?

Estas questões de pesquisa me conduziram para a hipótese de que o nome não é uma simples designação, mas parte do possuidor, um pedaço idêntico a ele, inseparável da pessoa. O nome é a própria pessoa.

Além do mais, em se tratando do povo Capuxu, os nomes e sobrenomes exercem uma dupla função: eles não apenas constroem a pessoa, mas servem como identificadores daqueles que pertencem ao grupo, contribuindo para a constituição da identidade do povo. Por esta razão, entendo que a onomástica Capuxu é bastante reveladora da construção da pessoa e do modo como ela, através do nome, é entrelaçada ao grupo, compartilhando com os demais sujeitos uma mesma identidade. Neste caso, o sistema de nominação é um importante idioma revelador das relações de parentesco - especialmente neste sistema endogâmico - da construção da pessoa e da produção e compartilhamento da identidade Capuxu.

\section{SOBRE A IMPORTÂNCIA DOS SISTEMAS ONOMÁSTICOS}

Desde o ensaio clássico de Marcel Mauss (2003) e do ensaio de Geertz (1989), a antropologia tem concebido o estudo dos nomes como parte integrante de qualquer abordagem ao conceito de pessoa. Mas, os modos de nomear atendem a diferentes regras, que variam de sociedade para sociedade.

Pensando nisso é que eu me interesso pela conexão entre as formas de atribuição de nomes e a construção da pessoa e da identidade neste grupo camponês endogâmico. Busco, assim, entender a onomástica Capuxu em seus próprios termos, ou os modos e sentidos de classificação das pessoas nesta comunidade, afinal nomear é classificar (Lévi-Strauss 2003).

Como nos diz Ramos (2008: 60) "a sociedade reutiliza um código de classificação social para dizer algo mais, abrindo uma fresta para áreas mais recônditas da vida social". Logo, todo sistema de nomeação revela mais do que os nomes dos sujeitos que compõem uma sociedade, através das regras implícitas de nomeação este sistema evidencia muitos outros aspectos da comunidade, desde suas formas de parentesco até a construção das teias de relações sociais mais diversas. 
Roberto DaMatta (1976) entre os Apinayé descobriu os nomes pessoais como mecanismos para estabelecer relações sociais. Entre eles os nomes são transmitidos dentro de certas linhas de parentesco, especialmente entre tios e sobrinhos. Assim, papéis sociais são transmitidos juntos com os nomes próprios. Já Alcida Ramos (2008) observou entre os Sanumá que o nome os individualiza, chegando a ser um segredo sabido apenas pelos pais e pela própria criança.

Isso prova que em determinados sistemas a gestão onomástica ou os modos de atribuição de nomes são mais importantes do que os nomes por eles mesmos. Neste sentido, o mais importante no estudo da onomástica é perseguir o material semântico ou a matéria-prima com que se produzem os nomes (Ramos 2008). Os nomes próprios são a fonte para entender a lógica da vida social.

Evans-Pritchard (2002) demonstrou que entre os Nuer os nomes próprios são marcados pela mentalidade pastoril deste povo, pois os homens são chamados por nomes que dizem respeito à forma e cores de seus bois favoritos e as mulheres recebem os nomes de bois e de vacas que elas ordenham. Os meninos pequenos também se chamam uns aos outros por nomes de bois quando brincam nos pastos e a criança geralmente recebe o nome da cria da vaca que ela e sua mãe ordenham. Quando nascem, homens recebem nomes de bois ou vacas. Os chamados nomes-de-gado podem ser legados à posteridade, mas não os que receberam ao nascer, revelando-se assim uma identificação linguística de um homem com seu boi predileto. Se a lógica pastoril inerente ao pensamento Nuer aparece também em sua onomástica, esta é uma prova de que o sistema de nominação de um povo revela muito a respeito de sua própria cosmologia e do seu modus vivendi.

Penso em como o povo Capuxu consegue garantir, com uma repetição tão comum de sobrenomes e nomes próprios de geração a geração - num repertório tão curto, típico de um grupo camponês endogâmico - a distinção destes indivíduos com nomes e sobrenomes que se confundem. Como nomes próprios ao longo dos anos se transformaram em sobrenomes e apelidos? Que função social cumprem os apelidos? É isso que tentarei elucidar agora.

\section{TRANSMISSÃO OU HERANÇA DOS NOMES CAPUXU}

Margarida Maria Moura (2010) se dedicou ao legado dos nomes de batismo ou de pia em comunidades rurais do Rio de Janeiro, Minas Gerais e Maranhão. Conforme a autora, a nominação constitui a pessoa, sendo significativa para o grupo social ao qual a criança pertence. O nome é a primeira herança que se recebe da geração ascendente, o primeiro item social que se herda, cunhando a criança no nascimento.

Também na onomástica Capuxu uma das primeiras regras perceptíveis é a transmissão de nomes. Através da observação das complexas e exaustivas genealogias de parentesco, descubro uma transmissão freqüente dos nomes próprios, os chamados "nomes de batismo" ou "nomes de pia" que obedece a determinadas regras de nomeação.

Esta transmissão parece fragilizar a hipótese de que a função primeira do nome seria a individuação, afinal, conforme nos diz Bodenhorn e Vom Bruck (apud Viegas 2008) quando o nome que se tem é indicativo da pessoa que se é partilhá-lo pode ser particularmente problemático ${ }^{3}$. 
Entretanto, fica evidente a partir das genealogias do povo Capuxu que no passado essa transmissão ou herança dos nomes era a mais forte característica da onomástica do grupo. Com o passar do tempo os nomes se tornaram cada vez mais importados, passando o sistema de nominação por profundas transformações. Isto ocorreu gradativamente, mas especialmente a partir das décadas de 1980 e 1990, quando houve a aproximação dos Capuxu com os outsiders ${ }^{4}$.

A partir disso é que me utilizo aqui da diferenciação de Viveiros de Castro (1986) entre sistemas endonímeos e exonímeos. Neste último caso, adquirem-se nomes fora do universo social de pertença e vêem-se os nomes como um atributo não transferível ${ }^{5}$.

Entre os Capuxu percebe-se que o sistema se configurava como endonímico na medida em que boa parte dos nomes era transmitida dentro do próprio grupo, pelos antepassados, com a transmissão dos nomes a partir de um estoque limitado e em perpétua circulação. Com o passar do tempo, o sistema se transformou, passando a acatar alguns nomes trazidos de fora do grupo, caracterizando-se como exonímico.

Nos últimos anos, os nomes das crianças Capuxu tem se tornado nomes cada vez mais populares, que estão no auge na mídia, nomes de filhos de famosos ou até mesmo nomes estrangeiros, tendo sido o legado do nome deixado para trás.

Atualmente o sistema de nominação Capuxu não pode ser considerado fechado, apesar do fluxo de nomes que ainda o percorre de dentro do próprio grupo, ou seja, desta utilização profunda do repertório de nomes desde a primeira geração do grupo de que se tem notícia, já que essa abertura para nomes de fora torna-se mais evidente nas últimas gerações.

Isto ocorre por conta da transformação que caracterizou o grupo no que diz respeito a sua identidade coletiva, afinal a identidade Capuxu era como um estigma, as relações com os outsiders seguiam tensas, e havia uma negação do etnônimo. A partir dos anos de 1980 ocorre a aproximação do povo Capuxu com a cidade, as crianças passam a se destacar nas escolas, o povo se destaca em relação à festa da padroeira, com o time de futebol local e há uma inversão no estigma. Ele passa também a ser um importante reduto de votos para os candidatos à prefeitos e vereadores do município. Junto a esta aproximação do povo com os outsiders, veio a importação dos nomes próprios e o sistema começa a se modificar passando de endonímico a exonímico.

No que diz respeito aos sobrenomes, no caso Capuxu todos possuem praticamente os mesmos sobrenomes. Numa comunidade cuja sociabilidade é dada pelo "aqui todo mundo é parente", sendo esta a narrativa comunitária, os sobrenomes não teriam sentido como elemento de diferenciação, uma vez que

para que o sobrenome ganhe sentido como distintivo familiar, ele tem que actuar de dois modos interdependen $\neg$ tes: a) distinguir-se no contexto da comunidade; b) ganhar de modo mais ou menos intenso um significado de identificação familiar e de transmissão gene $\neg$ alógica (Viegas 2008: 85).

Os sobrenomes são oriundos dos casamentos primeiros, situados na origem da comunidade. Entretanto é preciso destacar que no passado os cartórios não eram tão rigorosos em relação aos registros de sobrenomes. 
existentes entre os nomes das famílias de seus pais. Isto já resultaria em quatro sobrenomes, que variavam nos registros dos filhos de uma mesma família.

Com os poucos casamentos exogâmicos que ocorreram, mais alguns sobrenomes adentraram na comunidade. Por isso, observando as genealogias percebemos que nas primeiras gerações eram estes quatro sobrenomes - Ferreira, Menezes, Lima e Costa - os que prevaleciam. Com o passar do tempo sobrenomes como Dias, Macedo, Pereira e Alves aparecem, mas não com tanta freqüência quanto os quatro primeiros.

Opto aqui por utilizar as categorias nativas para diferenciar as partículas ou diversos elementos que compõem o que chamamos de nome de uma pessoa. O nome próprio ou o primeiro nome equivale ao nome de registro, de pia ou batismal, é o chamado nome formal. Ele pode ser simples se equivale a apenas um nome ou composto se carrega consigo um segundo nome próprio.

O sobrenome é o nome de família, que vem em seguida ao nome próprio simples ou composto e entre os Capuxu segue a regra de sobrenome materno seguido do sobrenome paterno, os dois sendo patrilineares. Atualmente esta regra é mais evidente, visto que nas primeiras gerações existiam muitas crianças com patronímicos apenas maternos ou paternos, embora pertencendo a famílias nucleares estruturadas com pais e filhos no mesmo lar.

Não há entre os Capuxu uma busca de significados ou sentidos para os nomes, uma vez que os nomes seriados são os que prevalecem na comunidade. João de Pina Cabral (2007) atentou para esta repetição nas iniciais dos nomes de registro de nascimento extremamente comum na atualidade, e os classificou como nomes seriados ou serialidades. Estes nomes foram definidos por João de Pina Cabral, a partir do estudo em Valença (Baixo Sul baiano) como casos em que

vários filhos têm nomes iniciados com a letra ou a sílaba inicial do nome do pai; quando se dá a um filho um nome que conjuga sílabas de ambos os pais; quando as letras iniciais dos nomes dos filhos formam um acrónimo; quando os nomes de dois filhos são iguais excepto pela sílaba final; quando os nomes de duas gémeas são constituídos pela mesma série de letras, num caso lidas numa direcção e no outro na direcção oposta; etc. quebrar a serialidade é o esperado. É raro uma serialidade fechada, sistemática ou completa (Pina Cabral 2007:26).

Ademais, as impressões atribuídas a cada nome são relativas, variando bruscamente de pessoa para pessoa. Ora, mas se não parece haver busca de sentidos nos nomes atribuídos às crianças, certamente há sentido na escolha do nome, nesta espécie de gestão onomástica. O contexto social atribui sentido a esta escolha ao mesmo tempo em que é constituído por essa escolha. Como no sistema Tupinambá (Silva 1986), o mais importante aqui não são os nomes por eles mesmos, mas o modo como os nomes foram adquiridos. Por essa razão acredito que os sistemas de nominação são importantes denunciadores da lógica das relações numa comunidade, especialmente das relações tecidas através das crianças.

Ter uma criança é ganhar a oportunidade de dar um nome, e o poder de dar um nome pode ser uma dádiva concedida aos amigos, vizinhos, demais filhos, etc., uma maneira de fortalecer os laços sociais com os escolhidos, ao mesmo tempo em que o nome escolhido, se for legado, herança de alguém, ata os laços entre os pais da criança, o nominador e o epônimo ${ }^{6}$. Entretanto, embora qualquer um possa se tornar nominador, sugerindo nomes para as 
crianças ou indo buscá-los em qualquer parte, dentro ou fora da comunidade, só os pais podem registrar a criança em cartório, formalmente. Mas se os nomes são herdados, em geral os nominadores são os pais, que decidem quem será homenageado ou quem serão os epônimos.

Os nomes próprios são, além de desígnios do portador a que se refere, modos de associar pessoas, especialmente da família. Nesse sentido os nomes herdados são privilegiados na construção de associação entre pessoas, ele liga a criança ao seu epônimo, ao passo que fortalece a relação entre o nominador e o epônimo e entre a criança e o nominador. Assim, essas teias são construídas cada vez que um nome é herdado.

Mas outras teias são também tecidas quando o nome é atribuído. Por exemplo, dar aos padrinhos o direito de escolher o nome do afilhado, ocorrência comum entre os Capuxu, é uma forma singela de demonstrar consideração e respeito, fortalecendo os laços entre os padrinhos e a criança e entre compadres.

O intuito da reflexão que por ora faço é situar-nos num espectro de relações entre nomes, pessoa e identidade além da territorialidade, uma vez que um repertório de nomes com um estoque fixo e limitado garante semelhança e continuidade histórica, demarca o grupo e o seu território, forja a pessoa e a identidade Capuxu, mas por outro lado também se utiliza dos nomes como um fator de expansão, de individuação e de diferenciação, garantidor de mudança e descontinuidade histórica. Seria essa a ambigüidade da onomástica Capuxu? Apesar da ambigüidade e da função que esta cumpre, com o passar do tempo o sistema mudou de endonímico para exonímico.

Através da análise da onomástica Capuxu não é possível detectar apenas uma regra de atribuição de nomes, mas um complexo sistema de atribuição de nomes que se caracteriza pela transmissão em diversos sentidos ou pela atribuição livre?.

É preciso considerar a complexidade identitária do fenômeno da nomeação entre os Capuxu, especialmente no caso desta comunidade endogâmica com parentesco generalizado onde os sobrenomes já constituem um curto estoque unido durante gerações a um parco leque de possibilidades de nomes próprios. Assim, com uma matériaprima disponível muito limitada de nomes e sobrenomes, as repetições tornam confusas as genealogias. Por essa razão, o nome pessoal ou de batismo se torna ainda mais revelador da construção da identidade e individualização dos sujeitos.

Por isso talvez tenham se modificado as estratégias de nominação da comunidade. Quando se muda a onomástica mudam as relações e o contrário também é verdade. Cada vez mais dispostos a relacionar-se com o forasteiro, importam-se nomes para a comunidade.

Entre os Capuxu, a transmissão ou herança dos nomes atua numa série de vetores que a orienta. Os nomes podem ser transferidos seguindo uma regra de gênero se são herdados pela menina da avó/mãe/tia/prima ou pelo menino se são herdados do avô/pai/tio/primo.

No caso dos nomes herdados da mãe, não há um elemento específico (o chamado tecnônimo ${ }^{8}$ ) que diferencie o nome da criança e seu sobrenome dos da mãe - portando as duas nomes e sobrenomes completamente idênticos.

Exemplo: Senhorinha Maria de Santana (mãe)/Senhorinha Maria de Santana (filha) 
No caso dos nomes herdados pelas meninas de suas avós ou tias é comum o uso de um elemento identificador no final do nome, como Neta ou Sobrinha.

\section{Exemplo: Felicidade Ferreira (avó)/Felicidade Ferreira Neta (neta)}

Nos casos em que os nomes herdados pelos meninos vêm dos avôs/pais/ou tios e primos é comum um tecnônimo identificador como Filho/Júnior/Neto/Sobrinho.

Exemplo 1: Henrique Ferreira Costa e seu filho, Henrique Ferreira Costa Filho.

Exemplo 2: José Ferreira, cujo primo foi designado José Ferreira Primo e seu filho José Ferreira Filho (embora observe-se que a criança deveria se chamar José Ferreira Primo Filho, mas o acúmulo de dois tecnônimos não é comum).

Interessante perceber que o uso do tecnônimo filho/júnior/neto/sobrinho/primo faz romper com a regra de transmissão de sobrenomes da comunidade, que segue sempre a ordem: nome próprio + sobrenome paterno (patronímico) da mãe + sobrenome paterno (patronímico) do pai. É que no caso dos nomes em que é feito uso do tecnônimo o nome da criança deve seguir a ordem exata daquele de quem herdou e sendo acrescido apenas o tecnônimo, no final.

Conforme a análise da onomástica, os filhos mais velhos ou os primogênitos herdam mais nomes dos que os mais novos, embora às vezes os primogênitos herdem os nomes de pais e avós, e os mais novos nomes de tios e primos, especialmente se as famílias são numerosas, exigindo-se maior criatividade dos pais na hora de transmitir ou atribuir os nomes.

Assim, os nomes dos sujeitos Capuxu se repetem em demasia, pela possibilidade de serem herdados em vários sentidos: de pai para filho, de mãe para filha, de avós para netos e entre tios e sobrinhos ou até primos. Com tantos nomes repetidos a elaboração de uma genealogia é dificultada e eles mesmos se confundem sobre a que sujeito se referem, a que geração este "João" pertence, evidenciando-se assim mais uma importante função social do nome entre os Capuxu: a de definidor de geração.

Ademais, há uma regra curiosa de transmissão de nomes. Se uma criança, já portadora de um nome, vem a falecer, e em seguida os pais geram um novo rebento, ele ou ela receberão o nome e sobrenome do irmão que morreu. Isso foi verificado por mim nas genealogias ao observar na mesma geração duas crianças com nomes completamente idênticos, filhas dos mesmos pais. Só então atentei para o falecimento precoce da primeira criança, de quem o nome teria sido dado à irmã que nasceu alguns anos depois.

Exemplo: Terezinha Ferreira de Oliveira (nascida em 1966 e falecida)/ Terezinha Ferreira de Oliveira (nascida em 1968, falecida em 2009). 
Além desta transmissão de avó/mãe/tia/prima ou de avô/pai/tio/primo obedecendo a regra do gênero, os nomes também podem ser masculinizados se são femininos ou transformados em femininos se são masculinos. Por exemplo: se o pai é Paulo e a filha é denominada Paula, ou se a mãe se chama Luiza e o filho passa a se chamar Luiz. A inversão de nomes compostos também pode cumprir a mesma função, como no caso da mãe que se chama Maria José e cujo filho foi designado José Maria.

É comum a prática dos chamados nomes compostos, assim as crianças Capuxu possuem quase sempre dois nomes próprios, sendo geralmente chamadas apenas pelo primeiro nome. Às vezes na transmissão dos nomes os pais atribuem aos seus filhos o seu próprio nome como segundo nome da criança.

Exemplo: Vicente Alves da Costa atribuiu ao seu filho o nome de Manoel Vicente Alves da Costa.

Como vimos, entre os Capuxu é comum a transmissão dos nomes do pai/tio/avô/primo seguidos de partícula tecnonímica: filho/júnior/sobrinho/neto/primo. Assim, mais do que se atribuir um nome à criança repetese integralmente o nome do pai, avô, tio, primo, numa espécie de homenagem. Esta homenagem reside em merecimento, pois não se transmite a um filho o nome de alguém que não mereça ${ }^{9}$.

Ora, se no caso dos nomes herdados não se tem dúvidas de quem foi o homenageado, resta saber quem é responsável pela homenagem. Ao contrário do que pensamos, não é a criança, mas quem lhe atribuiu o nome, afinal é o sistema que nomeia crianças, o nome é uma imposição a estas. Adiante veremos como o sistema de alcunhas segue em direção oposta, uma vez que a escolha dos apelidos é das próprias crianças, o que revela a importância da agência infantil.

O mais importante é que há uma permuta implícita na homenagem, embora acredite-se que atribuir a uma criança o nome de seu pai seja um modo de fortalecer a relação entre a criança e seu pai. Esta pode ser uma estratégia de relação entre os cônjuges, especialmente se é a mãe quem decide dar o nome do marido à criança.

Entretanto, não parece haver ligação entre as vidas ou os destinos do sujeito cujo nome foi herdado de seu pai ou avô e estes indivíduos. Não podemos, portanto, afirmar que a identidade de outrem esteja presente nos atos formais daquele cujo nome foi herdado (Pina Cabral 2007). Este autor chamou esta transmissão do nome paterno, que é o tipo de transmissão mais comum de lógica de nomeação, de "em nome do pai".

Como vimos, quando ocorre a transmissão do nome do epônimo, seja ele masculino ou feminino, a regra de sobrenomes (patronímico do pai + patronímico da mãe) é quebrada. Assim é que a homenagem “em nome do pai" quebra a bilateralidade dos sobrenomes que a princípio são herdados pelas crianças de seus pais.

Mas esta repetição na íntegra do nome não ocorre para as mulheres. Mesmo quando a homenagem é feita, ela repete apenas o nome próprio, salvo raríssimas exceções, em que se repete o nome tal qual o do epônimo seguido de partículas tecnonímicas como sobrinha ou neta.

Entre os Capuxu há indivíduos com sobrenomes apenas paternos, apenas maternos ou com ambos. Mas o sobrenome implícito a todos eles, embora ele nunca tenha se tornado oficial, é o Capuxu, uma vez que, fora do 
grupo, onde a identificação se faz necessária, todos são conhecidos através do nome próprio e o epíteto Capuxu em seguida atuando como uma espécie de sobrenome.

De modo geral estas são as regras de transmissão de nomes entre os Capuxu:

a) Adquirido do pai tal qual, incluindo sobrenome, com os elementos Filho ou Júnior no final;

b) Adquirido do pai com sobrenome diferenciado (sendo acrescentado o sobrenome materno) sem algum elemento que o identifique no final;

c) Adquirido da mãe;

d) Adquirido da avó ou do avô materno ou paterno com ou sem tecnônimo;

e) Adquirido do primo, o que é mais raro;

f) Adquirido do tio ou tia materna ou paterna com ou sem elemento identificador;

g) Adquirido do pai pela menina ou da mãe pelo menino;

h) Adquirido da irmã ou irmão falecido.

\section{ATRIBUIÇÃO LIVRE: OS NOMES SERIADOS}

Afora a herança dos nomes, estes podem também ser atribuídos livremente. A atribuição livre é caracterizada pela escolha ou sugestão de nomes quaisquer, sem que sejam herdados de parentes ou antepassados. As crianças são nomeadas por pais, avós, tios e padrinhos. Os irmãos mais velhos também sugerem nomes aos irmãos mais novos, sendo todos estes nominadores em potencial. Nomes bíblicos e de santos também são considerados, especialmente os nomes de santas tidas em alta conta no hagiológio sertanejo ${ }^{10}$.

Atribuem-se nomes bíblicos se a família é religiosa ou não, somente por considerá-los bonitos. Quando os nomes são de santos do panteão católico, geralmente se escolhe a partir da história do santo, de características como luta, bravura, coragem ou generosidade. Há quem diga que a criança pode seguir o mesmo destino daquele santo cujo nome lhe foi dado, com uma vida marcada pelas características que o definiam.

Alguns nomes próprios transformaram-se ao longo do tempo em sobrenomes. Famílias tradicionais do Sítio Santana-Queimadas foram e são caracterizadas por um nome próprio composto de um patriarca que se tornou sobrenome, sendo passado aos filhos e de geração a geração desde então. Isto pode ser verificado no caso da família Juvino, cujo pai se chamava Juvino Salviano e atribuiu aos filhos os nomes de José Juvino, Maria Juvino, Praxedes Juvino, Otávio Juvino, Juvino Salviano Filho, dando origem a partir de então a toda uma descendência dos Juvino. $O$ mesmo foi verificado com os sobrenomes Abílio, Aprígio e Vicente.

A prova de que estes nomes próprios transformados em sobrenomes continuam sendo passados de geração a geração é que um dos filhos de Juvino Salviano, aquele que recebera o nome do pai, Juvino Salviano Filho, designou assim seus filhos: 


\author{
Manuel Juvino Costa \\ José Juvino Costa \\ Cícero Juvino Costa \\ João Juvino Costa \\ Porfírio Juvino Costa \\ Francisco Juvino Costa
}

Tendo fugido a regra apenas a criança de sexo feminino nascida na família, Maria Inácia do Rosário.

Outro exemplo. O senhor Abílio Alves da Costa, casado com a senhora Praxedes Alves de Maria, assim nomeou seus filhos:

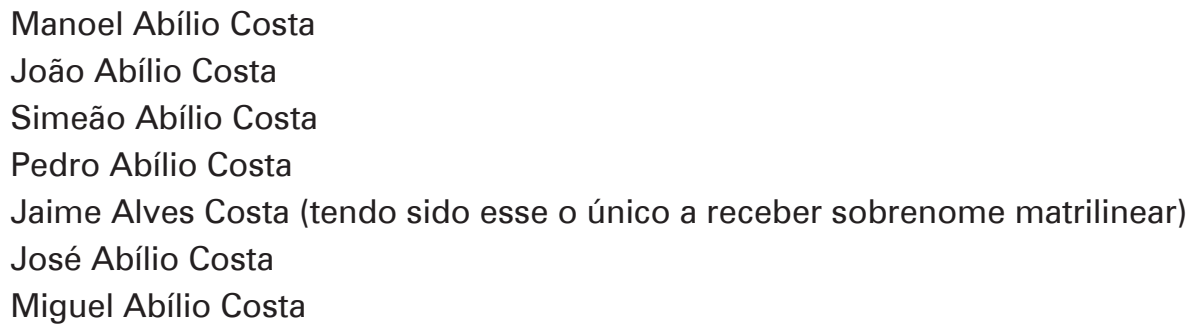

Manoel Abílio Costa

João Abílio Costa

Simeão Abílio Costa

Pedro Abílio Costa

Jaime Alves Costa (tendo sido esse o único a receber sobrenome matrilinear)

José Abílio Costa

Miguel Abílio Costa

A partir destes dois exemplos, não podemos deixar de considerar que há uma característica de transmissão nisso. Entretanto, levando em conta como estes nomes foram montados, sendo transmitido apenas um dos nomes próprios (o segundo nome dos chamados nomes próprios compostos), entendo que houve uma nomeação escolhida livremente.

Uma prática comum é a dos nomes próprios compostos em que o primeiro se repete para todos os filhos e em que se modifica apenas o segundo. Esta repetição do primeiro nome é muito comum para Maria, Ana e João. Assim, numa família inteira todas as mulheres se chamam Maria, com variação do segundo nome. Ou os homens todos se chamam João, com variação de segundo nome. Numa família específica eu encontrei uma repetição incomum, em que boa parte das mulheres se chama Edina, com variação para o segundo nome apenas. Outras meninas da família receberam nomes distintos e não houve regra para a nomeação dos meninos.

Segundo Pina Cabral (2007) as serialidades onomásticas reforçam relações sociais. Por essa razão acreditamos que a lógica de um sistema de nomeação informa as relações tecidas numa dada comunidade. Os jovens Capuxu cujos nomes são seriados e todos os irmãos cujos nomes começam com as mesmas sílabas disseram-me acreditar que isso os torna mais unidos.

Quando não se repete o primeiro nome em todos os filhos do mesmo sexo, pode-se também atribuir nomes começados com a mesma letra, assim uma família atribuiu a todos os filhos nomes iniciados com a letra $\mathrm{W}$, e isso se repete em várias famílias com iniciais $E, F$, L, etc. 
Exemplo 1: Maria da Conceição dos Santos Ferreira e Antonio Ferreira Sobrinho nomearam assim seus filhos:

Elba dos Santos Ferreira

Elder Santos Ferreira

Everton Santos Ferreira

Exemplo 2: Maria Bernadete Menezes Costa e José Ferreira Neto designaram seus filhos da seguinte maneira:

Felicidade Ferreira Neta (único nome transmitido com tecnônimo)

Wesley Costa Ferreira

Wellington Costa Ferreira

Yasmin Costa Ferreira (único nome não transmitido sem a primeira letra sendo W)

Wallisson Costa Ferreira

Wendel Costa Ferreira

Observamos neste exemplo um aspecto interessante: somente as crianças de sexo feminino não obtiveram nomes iniciados com a letra W.

Exemplo 3: Maria Ferreira de Lima e Domingos Pereira de Lima nomearam assim seus filhos:

Aldir Ferreira de Lima

Altemar Ferreira de Lima

Albanete Ferreira de Lima

Aldinete Ferreira de Lima

Albanisa Ferreira de Lima

Albanira Ferreira de Lima

Altamira Ferreira de Lima

Aldirene Ferreira de Lima

Almir Ferreira de Lima

Aldemir Ferreira de Lima

Observamos que os nomes dos membros das famílias mais antigas, primeiros nomes da comunidade, eram herdados dos antepassados. Com a herança dos nomes tendo ficado para trás, a serialidade despontou como regra maior do sistema onomástico Capuxu. 
Portanto, os nomes seriados ou a homonímia - semelhança de nomes - também podem fortalecer a relação entre pessoas Especialmente numa família cujos nomes dos filhos são todos parecidos isso parece torná-los mais unidos, ou pelo menos eles acreditam nisso. Mas as regras também podem ser observadas na ausência delas, numa família cuja regra foi colocar todos os nomes dos filhos diferentes, eles terminam por ser associados a esta diferença.

O emaranhado do sistema de nominação Capuxu se agrava pelo fato de, num curto repertório de sobrenomes - prevalecem quatro (Ferreira, Menezes, Lima e Costa) entre quase duzentos habitantes - os nomes próprios se confundem através da transmissão e legado dos nomes. Percebo como atualmente entre eles os nomes próprios diferenciados são de suma importância, uma vez que o estoque de sobrenomes é limitado. Sendo, pois, o estoque de nomes próprios ainda não muito variado, mas tendo começado a mudar apenas nas últimas décadas, surgem os apelidos como estratégia de diferenciação dos sujeitos, embora estes sejam, muitas vezes, também herdados.

Ademais, são verificadas duas práticas nas gerações mais antigas que reforçam os nós de parentesco com sobrenomes idênticos. A primeira delas é a prática do sororato, sistema em virtude do qual um homem substitui a esposa falecida pela irmã mais nova desta, o que fez Benjamin Ayres de Oliveira, advindo de fora da comunidade, casando-se com Maria José Alves Ferreira e após o falecimento desta contraindo novo matrimônio com Maria das Mercês Ferreira, irmã de sua esposa falecida. O mesmo ocorreu com Joaquim Filipe Velho, que se casara primeiro com Antônia Maria da Conceição, e em seguida com Francisca Maria da Conceição, irmã de sua primeira esposa, falecida.

Há também registros de casos, na origem da comunidade, de casamentos entre tios e sobrinhas. Foi o que ocorreu após o primeiro casamento trocado entre dois irmãos, Salviano Alves Costa e Vicente Alves Costa, e duas irmãs, Praxedes do Espírito Santo e Maria da Conceição. Outro irmão deles dois, Juvino Alves Costa, contrai matrimônio com uma das filhas de seu irmão (Joaquina Vicente), fruto do casamento entre Vicente Alves Costa e Maria da Conceição, tendo Juvino se casado com sua sobrinha legítima.

Estas duas práticas, sororato e casamento entre tio e sobrinha, complexificam o sistema de nominação na medida em que os nomes próprios se repetem entre estas famílias e os sobrenomes também são os mesmos, dificultando a identificação dos sujeitos com o passar do tempo e a feitura de uma genealogia.

No passado as famílias eram numerosas, com uma média de dez filhos. O repertório de nomes era curto, prevalecendo os nomes de João, Maria, José, Terezinha, Francisco, Manoel, Antônio e Joaquim, além de alguns nomes bíblicos como Pedro, Paulo, Simeão, etc. Os filhos mais velhos herdavam mais nomes do que os mais novos.

As primeiras famílias da comunidade possuíam nomes próprios ou de batismo menos comuns como Senhorinha, Praxedes, Roseno, Salviano, Ananiana, Honorata, Apolônia, Porfírio, Belarmino, Anita, Guiomar, Auta, etc. Alguns destes nomes prevaleceram durante algumas gerações através da transmissão de pais para filhos, avós para netos, ou tios para sobrinhos Com o passar do tempo o repertório foi se renovando e passando a apresentar nomes cada vez mais comuns ao repertório da sociedade brasileira em geral, como Ana, Pedro, João, Maria, Paulo, nomes bíblicos em geral e de santos do panteão católico. Ana se tornou um nome comum por lá, inclusive por 
causa da padroeira Sant'Ana, embora não seja o mais comum.

Não encontrei entre os Capuxu casos de pessoas que portam nomes que as desagradem. Também não encontrei muitas associações entre o nome da criança e o referente: o santo, a bíblia, o herói, o homenageado.

\section{APELIDOS, ALCUNHAS OU CODINOMES: FORMAS JOCOSAS DE CLASSIFICAR}

Se as crianças Capuxu não herdam mais os nomes dos antepassados, um curioso fato continua ocorrendo: a atribuição de apelidos ou codinomes ${ }^{11}$. A quantidade de nomes repetidos num curto repertório onomástico fez com que as primeiras gerações das famílias Capuxu atribuíssem apelidos como uma estratégia para que pudessem identificar melhor os sujeitos. Estes eram atribuídos pelos próprios pais, irmãos ou primos, vizinhos e amigos, de modo que quase todos têm um apelido através do qual são conhecidos.

Ora, como se atribuem os apelidos? Quem os atribui? Que funções sociais eles cumprem? Quais os mecanismos de aquisição de apelidos?

Os apelidos são formas jocosas de classificar, uma maneira divertida de nomear. Estes apelidos podem nascer de um hábito percebido no sujeito (por exemplo: Manu, que significa comedor de coalhada) ou uma semelhança com alguém (um parente mais velho, uma figura caricatural do Sítio Santana-Queimadas), ou uma corruptela do nome. O fato é que todo apelido tem uma explicação para além de sua função social de diferenciar sujeitos sociais com tantos nomes e sobrenomes iguais.

Características físicas servem de inspiração para os apelidos. Semelhanças com parentes ou conhecidos também. Quando um apelido é evocado vem à memória um fato, uma circunstância, um personagem. Todavia, como alguns destes apelidos nascem de um hábito ou uma característica particular, marca da personalidade ou do corpo, eles são facilmente identificadas pela psicologia contemporânea como bullying, uma vez que são utilizados também para provocar risos, como motivos de gozação e brincadeiras entre amigos, para ridicularizar o sujeito a quem o apelido se refere. Entretanto, não me interessa aqui esta análise das conseqüências psicológicas que podem ser geradas por estes apelidos, mas a função social que eles cumprem e sua importância na onomástica Capuxu.

O mais importante é que estes apelidos são aceitos por aqueles que os recebem. No início são motivo de risos e, com o passar do tempo, passam a ser familiarizados de modo que só os forasteiros estranham-nos a ponto de perguntarem qual o verdadeiro nome do sujeito, o que significa aquele apelido ou qual a razão dele. A razão também pela qual estes apelidos são tão bem aceitos é que eles surgem geralmente na infância ou na adolescência. Com a aprovação de todos não há como recusá-los, ademais quanto mais se chateia a criança ou o adolescente com o apelido, mais os amigos o chamarão assim. No caso do povo Capuxu os principais responsáveis por colocar apelidos são as crianças.

Assim, as alcunhas acompanham as crianças Capuxu pelo resto de suas vidas. Muitas vezes as minhas tentativas de construção das genealogias eram interrompidas e dificultadas por causa da quantidade de apelidos. Se por um lado, havia o emaranhado de nomes próprios semelhantes, por outro os Capuxu logo diferenciavam estes sujeitos de gerações diferentes com o mesmo nome e sobrenome, ou até mesmo da mesma geração com 
o mesmo nome próprio, através dos apelidos. Noutros casos, na construção da genealogia de uma família, só dispunham do apelido do primo distante, sem que fosse mais conhecido o seu nome de batismo ${ }^{12}$. Era preciso dar início a uma investigação para descobrir o nome daquele sujeito a quem todos chamavam de "Véi de Buda", por exemplo, enquanto os mais velhos se esforçavam para saber qual era mesmo o seu nome de registro antes de ter sido designado com tal apelido.

Com a ajuda das crianças e dos adolescentes Capuxu, montei um quadro dos apelidos com os nomes de alguns sujeitos que assim designam e os significados de tais apelidos. Essa construção foi permeada de gargalhadas constantes e muita diversão em ver a curiosidade da pesquisadora em apelidos e significados. Se a familiarização com o apelido tira dele o seu humor, qualquer situação diante de um forasteiro em que se questione os apelidos os faz lembrar seus sentidos e é motivo de brincadeiras.

\begin{tabular}{|c|c|c|}
\hline Nome de batismo & Apelido & Significado \\
\hline Euzary & Zazá & Corruptela do nome \\
\hline Denise & Queidinha & \\
\hline Daniela & Maria dos homens & Gosta de jogar bola \\
\hline Felicidade & Lili & Corruptela do nome \\
\hline Juliana & Natide & $\begin{array}{l}\text { Usa um lenço na cabeça como uma } \\
\text { "velhinha" da comunidade que tinha esse } \\
\text { hábito e se chamava Natide. }\end{array}$ \\
\hline Ana Júlia & Banguela & $\begin{array}{l}\text { Desde a troca de dentes de leite o apelido } \\
\text { permaneceu. }\end{array}$ \\
\hline Wellington & Boró & \\
\hline Wallisson & Jaracá & \\
\hline Wendell & Guein & Tem jeito de gay \\
\hline Yasmin & Pópa & \\
\hline Tarcísio & Buriti & \\
\hline Thiago & Maria Galega & \\
\hline Marcelo & Manu & Comedor de coalhada \\
\hline Rewry & Baé & $\begin{array}{l}\text { Um homem gordo da comunidade que } \\
\text { gosta de jogar pife como ele. Porquinho } \\
\text { pequeno, gordo. }\end{array}$ \\
\hline Fabinho & Rabichola & Arengueiro; briguento. \\
\hline Joselito Júnior & Jegue & Tem dentes para fora \\
\hline
\end{tabular}




\begin{tabular}{|l|l|l|}
\hline Flaviane & Zé Violão & \\
\hline Riquelme & Titião ou Chico Suzana & $\begin{array}{l}\text { Titião é a corruptela de Tio Tião, um } \\
\text { idoso com quem ele briga o tempo todo; } \\
\text { e Chico Suzana é um taxista da cidade } \\
\text { com quem ele se parece fisicamente. }\end{array}$ \\
\hline Miguel & Profeta miguelzim & \begin{tabular}{l} 
É um advinhador de chuva \\
\hline Eliane
\end{tabular} \\
\hline Rayane & Liquinha ou potro & $\begin{array}{l}\text { Corruptela do nome ou espécie de } \\
\text { cavalo. }\end{array}$ \\
\hline Everton & Vozinha & $\begin{array}{l}\text { Em função de Rejane, idosa com quem } \\
\text { se parece. }\end{array}$ \\
\hline Elder & Tidedé & Semelhança com o Tio Dedé \\
\hline Ítalo & Tidão & Semelhança com o Tio Dão (João) \\
\hline Eron & Puca & \\
\hline
\end{tabular}

TABELA 1 - Apelidos de crianças e adolescentes ${ }^{13}$.

Ao contrário dos mais velhos, cujos apelidos já são fator maior de identificação dos sujeitos e cujos nomes de batismo ficaram perdidos da memória, as crianças e adolescentes lembram ainda com clareza do nome de batismo de cada um deles, dizendo o apelido, explicando-o e dizendo o nome do sujeito em seguida.

Esta lembrança avivada dos nomes pode também ser explicada pela presença deles na escola - com seus diários e nomes completos ou nomes de registro. Na fala da professora durante a chamada, uma pergunta ou uma repreensão os fazem lembrar dos "nomes verdadeiros" de seus colegas. Fora dela, do portão em diante, ou ainda pelos seus corredores, as crianças só se tratam pelos seus apelidos. Até aqui os nomes próprios estarão resguardados.

Encarregar-se-á o tempo de tornar estes nomes próprios, utilizados somente em ocasiões formais (batismos, primeira eucaristia, crismas, casamentos, óbitos) desbotados em registros que tudo isso comprovam, ou lembrados apenas por ocasião da passagem de uma antropóloga. Quando os nomes já forem esquecidos de suas memórias, eles tentarão a todo custo resgatar o "nome verdadeiro" daquele Capuxu que todos conheciam como Profeta.

Mas os apelidos que substituem, em termos, os nomes, são prova maior de aceitação social. Tê-los é estar imerso nas teias sociais que são tecidas pelo povo Capuxu, aceitá-lo é aceitar sua posição no lugar que a comunidade Ihe inscreve. Quem não os tem são aqueles que permanecem na fronteira da comunidade, entre o Sítio SantanaQueimadas e as cidades, cada vez mais distante de todos, casando-se para fora e afastando-se da comunidade.

Tal qual ocorre aos nomes próprios, os apelidos também podem ser herdados. Esse legado é também lúdico. Uma criança cujos traços lembram os do tio velhinho, figura caricatural do Sítio que é conhecido de todos 
por Tidão, corruptela de Tio Dão (Apelido de João), passa desde a infância a ser chamado de Tidão. A menina que tem por hábito amarrar um lenço no cabelo como a velha Natide passa a ter o apelido de Natide. Há não apenas um legado de nomes, mas um legado de codinomes.

Para os Capuxu os apelidos são o modo como são chamados informalmente ou por aqueles com quem tem intimidade, no caso do grupo, por praticamente toda a comunidade. Os apelidos dos Capuxu, como os nomes, são levados até a morte. Geralmente se ganha um apelido na infância e ele permanece ao longo da vida, podendo inclusive virar tecnonímico, quando as filhas e as esposas passam a ter como referência de sua própria identidade o apelido do pai ou marido. Ex.: Maria de Véi de Buda.

Entre os Capuxu os apelidos são sempre aceitos e nenhum deles é considerado maléfico, afetando negativamente o seu portador. Não se acredita que o apelido tenha outras implicações sobre a pessoa a não ser identificá-la.

Apelidos são nomes divertidos, uma forma jocosa de nomear, de se referir ao outro. Quem apelida alguém pode ter como vingança maior, ganhar um apelido para lhe fazer referência pelo resto da vida. Para a minha satisfação etnográfica, adoravam as crianças contar os apelidos umas das outras. Especialmente se o seu apelido é revelado, contar o apelido de outro é uma forma de vingança aceitável. Mas não são eles, os apelidos, motivos de brigas ou agressão moral. Não entre os Capuxu. Não nas fronteiras do Sítio Santana-Queimadas.

Dependendo da situação, especialmente se ela se passa na cidade, é pronunciada por um forasteiro ou tem um tom de ironia na voz, chamar o nome próprio de alguém da comunidade, seguido pelo designativo Capuxu, como se fosse um sobrenome, ou pronunciar seu apelido adquirido no Sítio pode parecer uma ofensa. Assim é que pronunciar um apelido pode ser sinônimo de amizade e intimidade ou uma ofensa, uma agressão a depender do modo como se pronuncia e, neste caso, do lugar. O mesmo era dito do termo Capuxu. Quando alguém da cidade pronuncia "ei, Juliana Capuxu", por exemplo, em tom de ironia, a criança ou adolescente se sente ofendida.

Porém, é necessário que se diga que entre eles, e nas fronteiras do Sítio Santana-Queimada ${ }^{14}$, os apelidos são dados e recebidos por amigos (e não inimigos) e legitimados por todos. Os nomes próprios também. Não se dá um nome a uma criança de alguém por quem se tem desafeto. Pelo contrário, em geral são epônimos aqueles com quem os pais se relacionam bem.

Se os apelidos garantem a socialização dos sujeitos e tecem jocosamente teias sociais, no caso dos Capuxu é correto dizer que não se pronuncia um nome em vão. Não, se se dispõe de um bom apelido.

Seria correto afirmar que os Capuxu exibem apelidos e escondem nomes? Nomes incorrem em rasuras fonológicas e não gráficas, ditas e não - nem sempre - escritas. Nomes próprios existem, mas são guardados, suspensos pelos Capuxu para serem utilizados nos momentos formais. No cotidiano usam-se os apelidos, mais informais, íntimos. Como diz Pina Cabral apelidos "são nomes que não se escrevem (...), dados pela comu $\neg$ nidade ao indivíduo (...) normalmente independentemente da sua escolha explícita" (Pina Cabral 1984: 150).

Alcida Ramos (2008), em análise sobre os nomes e o modo de ser Yanomami, percebeu que entre eles os nomes pessoais pronunciados revelam intimidade: “exatamente entre os Yanomani, onde não há privacidade 
física, há de nomes". No caso Capuxu é o contrário, apelidos revelam intimidade e nomes formais são revelados desde criança.

Se para Viegas (2008) os apelidos são nomes afetivos, com o que concordo, "derivam de corruptelas ou diminutivos do nome de registro, nomes que são também epítetos que podem derivar de certa particularidade física ou moral" (Viegas 2008: 79), penso que entre os Capuxu eles são também jocosos, além de ser maneiras de revelar intimidade. Entre gargalhas e brincadeiras, gritos e sussurros, as crianças Capuxu revelam apelidos próprios e de outrem, tornando o sistema de classificação de pessoas além de complexo, divertido.

A partir desta análise da toponímica Capuxu concebo uma forte relação entre o lugar e a construção da pessoa, uma construção marcada pela intimidade do lugar onde todos têm também nomes singulares, mas que, ao mesmo tempo, reforçam certas relações familiares. Penso que o lugar é um dos referentes principais na construção da pessoa Capuxu, na maneira como ela se torna um ser-no-mundo, como se constitui o processo referencial de parentesco a identidade e a gestão onomástica.

Logo, se o lugar é fundamental para a construção do corpo, como veremos adiante, com espaços profícuos para essa construção e, consequentemente, para a fabricação da pessoa, isso se torna evidente a partir do momento em que não só o parentesco e a identidade são calcados num lugar, mas também a onomástica. Determinados nomes próprios e sobrenomes circulam na fronteira do Sítio Santana-Queimadas, tal qual o desígnio Capuxu utilizado para todos que habitam aquele lugar. Também os apelidos são permitidos, sem se tornarem agressivos ou ofensivos, nas fronteiras do Sítio, lugar de intimidade onde são compartilhados a identidade, o parentesco, os nomes próprios e os sobrenomes.

Assim é que, em se tratando dos Capuxu, a pessoa também é um lugar. O lugar de um nome, talvez. Por esta razão, pode-se ouvir na cidade, "você vai nos Capuxu?", ao se referirem às idas ao Sítio onde eles habitam.

Por isso entendo que entre os Capuxu há modos de pertença ao espaço, demarcados também pela nominação. Por dinâmicas de nominação ou gestão onomástica, dada pela intimidade máxima entre aqueles que são da mesma área de habitação ou lugar, valorizando os laços de proximidade além dos identitários, deste modo se intensifica a experiência pessoal. Isso é tão verdadeiro que dois jovens cuja mãe Capuxu é falecida e o pai forasteiro nunca morou na comunidade casaram-se com forasteiros, saíram da comunidade, levaram consigo a aparência, o estereótipo e os sobrenomes Capuxu mas não receberam nenhum apelido, embora todos os jovens da mesma geração com quem eles cresceram juntos os tenham. A ausência de um apelido a circular nas fronteiras do Sítio demonstra distanciamento social.

\section{A RELAÇÃO COM OS ANIMAIS: OS NOMES E A APRENDIZAGEM CORPORAL}

No sertão é comum atribuir-se nome aos bichos, não havendo inominados. Não apenas os animais domésticos, como gatos, cachorros, mas todas as espécies animais que habitam com o povo o mesmo espaço são nomeadas, como vacas e bois, jumentos e até cabras. Esta é a regra no sertão, onde o que não tem nome não existe! 
Se aos homens a nominação é condição para a existência, assim parece ocorrer aos animais entre o povo Capuxu. Não existe um animal sem nome ou talvez, seguindo a regra da antropologia para os homens, um animal sem nome não existe, sendo esta atribuição não apenas infantil, mas também dos adultos. Entretanto, como os animais são uma companhia constante para as crianças, especialmente os chamados domésticos ou aqueles de dentro de casa, gatos e cachorros, é comum que o conhecimento dos nomes dos bichos seja maior por parte das crianças do que dos adultos ${ }^{15}$.

Se toda onomástica revela relações, devo dizer que entre o povo Capuxu os sistemas de nominação revelam relações entre homens e entre homens e bichos. A verdade é que a infância Capuxu, prenhe dos elementos que a cercam, como o meio ambiente e os animais, aproxima em especial as crianças dos bichos, embora a relação do homem do campo com os animais perdure por toda a vida.

Por isso na infância as crianças aprendem a respeitar os animais, conviver com eles, dividir os mesmos espaços, incluí-los em seus cotidianos. Como as crianças, os animais estão por toda parte do Sítio SantanaQueimadas. Mais do que tornarem-se brinquedos para as crianças, sua principal companhia nos dias da infância, as crianças aprendem dos animais e com eles. Uma série de descobertas a respeito de si mesmas e do próprio corpo são feitas pelas crianças através dos animais.

É também da fusão entre o espaço de crianças, o de adultos e o mundo animal que resulta as aprendizagens sexuais da criança camponesa ${ }^{16}$. Assim, a infância quase despudorada da criança Capuxu acontece nos espaços que a une a adultos e animais. Espaços sem limites ou fronteiras que intimidem a presença das crianças.

A observação do cotidiano das crianças revelará o quanto elas engatinham dentro de casa, tentando alcançar os seus gatos. $\mathrm{O}$ quanto meninos e meninas adormecem no chão frio da casa, encostados em seus cachorros. Como as crianças são levadas para longas jornadas, montadas em jumentos. Antes mesmo de aprender a equilibrar-se de pé, a criança Capuxu é capaz de montar e percorrer trajetos no lombo de um jumento ou cavalo. E como as crianças são capazes de atravessar currais passando por baixo de pernas de vacas para buscar o leite.

Também com os animais, as crianças aprendem a utilizar de maneira diferenciada e particular os espaços da casa: deitar no chão da sala, embaixo da rede, na soleira da porta. Por vezes, em espaços em que somente os animais se deitam. E aprendem também a dividir a comida com os bichos, dando-lhes com suas próprias mãos.

Certa ocasião uma criança de cinco anos argumentava com a avó para que essa não matasse uma galinha para comer no domingo. Ela dizia, "mas vó, você disse que as galinhas eram minhas" e de fato sua avó sempre dizia que todas as galinhas e pintinhos no terreiro pertenciam a ela, cedendo aos pedidos insistentes da menina que queria ser dona daquela fazendinha ${ }^{17}$. Depois de muito interceder pela vida da galinha, predestinada a virar cozido no almoço de domingo, a criança alegou: "Vó, a galinha é um ser humano!". Acostumada a ver na escola ou nos programas de televisão tantas vidas serem defendidas com esse argumento, a criança não hesitou, elevou a galinha à condição de humana. É assim que se relacionam as crianças Capuxu com os bichos.

Se para as crianças Capuxu os animais são como seres humanos (ou como pessoas), então eles são dignos de nomes também. Entendo que a intenção aqui é mais do que discutir nomes de bichos, é aprender aquilo que 
esta onomástica revela: as relações entre as crianças e eles, as fronteiras na construção da pessoa, e sobre a produção do corpo dada através desta relação. Afinal, penso que há uma aprendizagem delas através do corpo com os animais.

Qual a natureza desta relação? Ora, mas de que modo a aprendizagem corporal com os animais ajuda a produzir o corpo e a pessoa Capuxu? Qual a importância dos nomes dos bichos para a construção da pessoa Capuxu? As fronteiras entre a pessoa e a não-pessoa passa pelos nomes? Isso e tantas outras coisas podem nos ser reveladas pelo estudo sistemático da onomástica dos animais.

Observo que boa parte da aprendizagem corporal das crianças Capuxu se dá com os animais, de modo que a percepção do corpo da pessoa ou de si mesmo pode se dar através da descoberta do corpo do animal. 0 engatinhar, o morder-se, o lamber-se também são aprendidos. Também o bebê que deita imitando o cachorro, fecha os olhos apertado imitando o gatinho e corre cambaleante tentando acompanhar as galinhas. Dos animais, as crianças Capuxu aprendem ainda sobre o sexo, descobrem as relações entre machos e fêmeas através daquelas que se estabelecem entre os seus animais.

Desde criança os pequenos Capuxu são ágeis como gatos do mato, podendo se deslocar pela mata como um deles, e raivosos como cães, sendo brabos e destemidos quando se vêem caçoados ou ameaçados. No mais das vezes o seu temperamento é associado ao do seu bicho doméstico, ou vice-versa.

No que se refere às crianças, podemos dizer que os animais são os companheiros de diversão, das longas caminhadas para levar recados na casa de alguém, do sono vespertino no cimento frio da sala e na comensalidade, com almoços degustados pelo chão da cozinha. O bebê Capuxu consegue erguer-se do chão se apoiando em seu cão, e ensaia, enquanto tateia o corpo do animal, os primeiros passinhos.

No que concerne aos adultos, os animais são companheiros de trabalho, da labuta diária, na lida agrícola. Por isso não se pode nem se deve negar um nome ao companheiro tão fiel e tão presente no dia-a-dia do camponês.

Penso que a fronteira para a construção da pessoa pode passar, entre os Capuxu, pelos seres nominados e inominados. E o mais importante: quem mais atribui nomes aos animais são as crianças e isso, de certo, informa algo. Por que as crianças e qual é a matéria prima destes nomes?

Lembro-me que certa vez, durante um passeio matinal ao lado de Carminha, que, além de importante interlocutora, era minha anfitriã na comunidade, e seu filho Eudvan, de cinco anos, eu me espantei com o grito dele apontando para o matagal ao lado e gritando "Olha mãe, Pinguim!". Minha indignação foi completa, além do susto por ver algo se mexendo rapidamente por entre as plantas e o grito da criança, eu não podia conceber um pingüim em pleno sertão paraibano. O mistério foi rapidamente desvendado quando correu em nossa direção um simpático cachorrinho vira-lata, magricelo, preto e branco e Carminha sorrindo explicou “o cachorro lá de casa que estava desaparecido".

Pingüim, companhia constante de Eudvan, permaneceu ao lado do seu dono, durante nosso percurso. Adiante, enquanto Carminha parava para cumprimentar alguém na porta da casa de uma família Capuxu, Eudvan tirou do bolso um pedacinho de rapadura, comeu quase tudo de uma vez só e estendeu a mãozinha suja para que Pinguim a lambesse. Ficaram os dois saciados. 
Os animais domésticos, especialmente gatos e cachorros, são "propriedade" das crianças. Depois de certa idade elas devem alimentá-los, banhá-los, protegê-los no caso de ataque por outros animais, cuidar deles de modo geral. Estas passam a ser tarefas de responsabilidade das crianças.

Eudvan já foi dono de 87 pintinhos, uma verdadeira fazendinha. Ele era também uma espécie de "parteiro". É que, depois de chocados os ovos, os pintinhos vão aparecendo aos poucos, ao longo do dia, Eudvan podia, então, ir abrindo os outros ovos, cujos pintinhos estavam sentindo dificuldade em rachá-los. De cócoras, Eudvan procedia à abertura do ovo quebrando sua parte superior e com delicadeza retirando os pedacinhos da casca que o encobria. Avistando o pintinho, ele devolvia o ovo para o ninho e deixava que o próprio pintinho terminasse a tarefa de quebrar o ovo e se livrasse dele para sempre. Era também Eudvan o responsável por jogar milho ou farelo para as galinhas e os pintinhos e tanger as galinhas para o poleiro.

Dois dos meninos com quem conversei na escola disseram que, no futuro, quando crescessem, gostariam de ser vaqueiros, destes que competem em Parques de Vaquejada, e falavam inclusive que seus pais Ihes levavam em todas as vaquejadas que aconteciam nos arredores de Santana-Queimadas. Um deles contou que está juntando dinheiro para comprar um cavalo.

É interessante perceber que, em geral, todos os habitantes da comunidade sabem os nomes dos animais domésticos da maioria das famílias. Assim, sempre que chegávamos em uma casa para visitar alguém, ou onde nos uniríamos em almoços, cafés, jantares, era normal que a família que me acompanhava tratasse os animais que encontravam pelas estradas nas portas das casas de seus donos pelos nomes, fosse para cumprimentá-los, fosse para repreendê-los por estarem acuando a mim, ou me "estranhando"18, como dizem.

Outro interessante aspecto é que os animais domésticos são criados praticamente dentro de casa, os gatos ocupando cadeiras e sofás, os cachorros ocupando as soleiras das portas e os porcos, galinhas, galos e pintinhos ocupando os quintais e, vez por outra, invadindo os espaços da casa em busca de grãos ou farelos de cuscuz, pão, etc.

A infância Capuxu se caracteriza pela aproximação condescendente da criança e da natureza. As suas brincadeiras evocam e elencam elementos rurais. A criança personifica seres e objetos. Os seus brinquedos no mais das vezes são árvores, balanços, riachos e a terra.

Mas essa aproximação da criança com o meio tem seu ápice nas relações que se estabelece com os animais, especialmente com os animais de estimação. A criança Capuxu está rodeada de animais e cresce com estes a sua volta. Muitas vezes o seu animal doméstico é a sua principal companhia em casa e por toda parte, especialmente nos casos raríssimos onde há apenas um filho na família.

A relação da criança com os animais emerge na comunidade Capuxu nos primeiros meses de vida dos pequenos e chega a existir uma semelhança entres crianças e animais. É que as crianças crescem livres tal qual os animais (ou seria o contrário?). São estes dois, crianças e animais, que ocupam todos os lugares do Sítio a toda hora.

Juntos caminham pelas estradas e trilhas ou pela relva, matagal adentro. Juntos correm, levantando poeira tão alta nos verões dos anos fatidicamente secos que quase não podemos enxergá-los. Juntos almoçam sentados 
ao chão da cozinha ou de qualquer outro cômodo da casa. Vão juntos levar recados às casas da redondeza, vão à Igreja, à casa paroquial e à escola. Se o pequeno entra na escola e o seu animal é um cachorro, fica ele à espera na frente da escola, à mercê do tempo.

Os animais mais comuns do Sítio, de posse das crianças, são cachorros e gatos. As crianças brincam com eles, escolhem seus nomes, alimentam-nos e banham. Eles dormem dentro das casas ou em seus arredores. Seguem seus donos aonde quer que eles forem. São muitas vezes os grandes amigos das crianças, os seus diletos brinquedos ${ }^{19}$.

Mas há grande variedade de animais. Há aquelas crianças que preferem pintinhos ou galinhas, porquinhos ou patinhos, jumentos ou cavalos, cágados ou papagaios, bezerros ou cabritos, coelhos ou iguanas. Todos os animais são de agrado das crianças, mas os filhotes têm preferência na hora de tornarem-se amigos. É que no caso dos animais menores é mais fácil para as crianças terem-nos nos braços, no colo ou fazerem um afago.

Não é raro encontrarmos crianças abraçadas aos seus animais. Deitados juntos na sala enquanto vêem televisão e até mesmo, adormecendo em suas redes enquanto o animal se acomoda embaixo, velando o sono de seu amigo.

As crianças falam de seus animais constantemente, exibindo orgulhosas suas qualidades, como eles são bonitos, gordos, limpos, espertos e sabidos. Desprendem, pois, todo um carinho em relação aos animais. E não só falam deles, mas falam com eles. Dirigem-Ihes palavras de carinho e afeto, contam-lhes segredos, desabafam e brigam com eles por qualquer razão. Chamam-Ihes pelo nome gritando de longe e eles vêm felizes encontrarem seus donos.

Principalmente no caso dos cachorros, às vezes nem é preciso chamá-lo pelo nome. Basta um assovio, um gesto dos dedos e um "qui, qui" numa corruptela do "aqui, aqui" e eles vêm abanando o rabinho. Mesmo aquelas crianças com vocabulário minguado estabelecem uma relação prazerosa com os seus animais com monólogos e gestos de carinho.

Um interessante fator a ser mencionado é a ausência de medo das crianças com relação aos bichos. Elas atravessam uma manada, um rebanho sem qualquer temor. Ainda na primeira infância transitam pelos currais, aproximam-se de gado, de jumentos e de cavalos. Tentam alcançar as galinhas e agarrá-las. Nada as assusta.

E quando crescem mais um pouco, já começam a alimentar os animais, banhá-los, domesticá-los, e falam com aquela voz autoritária dos adultos segurando cipós na entrada do curral: “Ê, boi, ê...", “Vai!”, “Estrelinha! Gasolina! Gigante!", chamam os seus cachorros, tangem as vacas. Os seus animais amigos estão sempre ao seu lado. Depois voltam para casa e elas cuidam de alimentar seus gatos. Na infância Capuxu há sempre espaço para mais um bicho. 


\begin{tabular}{|c|c|}
\hline Bichos & Nomes \\
\hline Cachorro & $\begin{array}{l}\text { Caçador, Vencedor, Gigante, Nêgo, Pinguço, } \\
\text { Rabito, Pretinha, Baleia, Regues, Fofinha, Pretinho, } \\
\text { Mel, Ring, Estrela, Filó, Braqui, Vivian. }\end{array}$ \\
\hline Gato & $\begin{array}{l}\text { Rodrigo, João Neto, Xanin, Pedro Neto, Xuxa, } \\
\text { Marri, Mansinha, Bilu, Sinhá Mesa, Nina, Xadrez, } \\
\text { Leo. }\end{array}$ \\
\hline Bezerra & Moleca \\
\hline Vaca & Princesa, Moça Bonita, Estrelinha, Gasolina \\
\hline Jumento & Luís \\
\hline Coelho & Pintado, Branca, Evans e Couve \\
\hline Galinha & Lulu \\
\hline Porco & Brabim \\
\hline Louro/Papagaio & José, Mário, Tujuca, Galinha Pintadinha \\
\hline Cavalo & Ventania, Furacão \\
\hline Cágado & Molenga \\
\hline
\end{tabular}

TABELA 2 - Nominação dos bichos

Conforme a tabela acima, percebemos que os nomes podem revelar características dos animais que são físicas, como a cor do pelo (Branca, Nêgo, Pretinho, Pretinha, Mel, Pintado), o corpo (Rabito, Molenga), a espessura do pêlo (Fofinha), o peso (Baleia) e tamanho (Gigante), ou características que remetam a coragem, determinação, habilidades (Vencedor, Caçador). Percebo que o modo como nomeiam os animais, através de características físicas, remete aos mesmos critérios de escolha dos apelidos quando estes se referem a características do fenótipo, como vimos anteriormente.

É também possível atribuir aos animais nomes que remetem a temperamento (como Brabim - que vem de brabo ou zangado - Mansinha), e velocidade (Ventania, Furacão) que são também elementos da natureza.

Outro fator a ser destacado é a possibilidade de se atribuir aos animais nomes de pessoas, (José, Mário, Luís, Lulu, Evans, Rodrigo, João Neto, Pedro Neto, Nina, Leo) sendo este costume revelador do lugar que os animais ocupam na cultura Capuxu.

Isto porque o hábito de atribuir nomes de pessoas aos animais demonstra que as fronteiras entre pessoas e animais se diluem. Ainda que os animais não sejam considerados completamente como pessoas, por não possuírem todos os atributos de pessoa, a não proibição de atribuição a estes animais de nomes de pessoas demonstra que eles possuem alguns destes atributos. Afinal, nomes de pessoas colocados em animais nos fazem crer que há algo nestes que nos remete àqueles. 
Outrossim, se é possível ao animal ter nome de pessoa, comer dentro de casa, em algumas circunstâncias, ou ser enterrado com alguma dignidade, isto revela que o estatuto de pessoa pode ser atribuído, em parte, a estes. É isto que nos revelam os termos nativos.

Emilene Leite de Sousa é Doutora em Antropologia Social pela Universidade Federal de Santa Catarina (UFSC) e Professora Adjunta da Universidade Federal do Maranhão (UFMA). 


\section{NOTAS}

1 Conforme demonstrou Margarida Maria Moura (2010) em interessante estudo sobre o legado dos nomes na infância camponesa e também Ellen Woortmann (1995) sobre compadres, padrinhos e nomes entre colonos do Sul e sitiantes do Nordeste.

2 Aracy Lopes da Silva num estudo dos nomes Xavante oferece-nos, contudo, uma experiência diferente sobre o significado dos nomes entre eles e o seu peso ontológico. A autora afirma que o fato de as crianças Xavante não terem nome até muito tarde não implica que os nomes sejam insignificantes, mas sim que "o nome é uma carga demasiado pesada para o seu corpo frágil" (Silva 1986: 67).

3 Foi isso também que Harrison observou, no estudo que realizou entre os Manambu na Melanésia, onde se deve ter um enorme cuidado em escolher-se um nome para a criança que não esteja já "em uso": "todas as pessoas têm que ser completamente individualizadas pelos seus nomes e não podem existir homônimos contemporâneos" (Harrison 1990: 61).

4 Inspirada em Elias e Scotson (2000) chamo de outsiders aqueles povos que habitam os sítios vizinhos que fazem fronteira com o Sítio Santana-Queimadas, os moradores da cidade de Santa Terezinha, de Patos, e enfim, todos aqueles que convivem ou estabelecem relações cotidianas ou extraordinárias com o povo Capuxu e que não são Capuxu.

5 Os sistemas onomásticos ameríndios endonímicos acentuam a conservação dos nomes como uma espécie de patrimônio a ser transmitido entre gerações. Estes sistemas valorizam tanto a transmissão "interna" de nomes que, mesmo quando se adquire o nome fora do universo social, o objetivo é integrá-lo à transmissão intergeracional "dentro do grupo" (cf. Viveiros de Castro 2006 apud Hugh-Jones 2006: 89).

6 Epônimo (aquele de quem a criança recebeu o nome) é diferente de nominador (aquele que busca o nome para transmiti-lo à criança).

7 Faço aqui uma ressalva para o uso destas nomenclaturas que elegi. Entendo que todo nome é atribuído, seja ele transmitido (não deixa de ser uma atribuição) ou não. Todavia, opto por distinguir no rol de atribuições possíveis aqueles que são atribuídos por transmissão (ou herdados) daqueles que são atribuídos livremente, obedecendo a outros critérios como nomes de santos, de famosos, etc.

8 Os tecnônimos são conhecidos na antropologia, sobretudo, pelo uso inverso, em que os parentes mais velhos são chamados através dos nomes dos mais jovens ou por referência a eles (Needham 1954).

9 Também Codonho (2009) verificou entre os Galibi-Marworno que, quando se escolhe o nome de alguém para colocar num filho, este nome muitas vezes tem a ver com a admiração que se tem pela pessoa. Pois os indígenas acreditam que o nome passa a característica da pessoa para quem vai recebê-lo, "a criança vai trazer aquele dom da pessoa".

10 Gilberto Freyre (2003) trata dos nomes tirados das folhinhas marianas sempre presentes nas casas rurais. Segundo o autor, os nomes de santos impediam que o sétimo filho de uma família virasse lobisomem, receio que acomete os moradores de algumas áreas rurais.

11 Opto pelo uso do termo apelido por ser uma categoria local, sempre que me referir a codinomes ou designações.

12 Outra expressão utilizada pelos Capuxu com menor frequência é "nome de casa".

13 A construção da etnicidade do povo Capuxu é caracterizada por uma autoestima elevada em relação a sua identidade. Estudando entre eles há mais de dez anos afirmo que não apresentar os seus nomes neste trabalho seria uma ofensa. A cada publicação o povo busca meus trabalhos para ler a histórias, ver fotografias e buscar seus nomes, sempre orgulhosos por terem "aparecido" e pelo seu sistema onomástico. Para mim é sempre mais difícil a tarefa de explicar aos Capuxu por que nem todos foram citados.

14 Pensar a importância do nome próprio e dos apelidos dentro e fora das fronteiras do Sítio e o modo como eles mudam de sentido a depender do lugar onde é pronunciado remete-nos à importância da territorialização para a questão dos nomes.

15 Assim, teríamos dois grupos de animais, os de pequeno porte e de dentro de casa, cuja companhia constante seria das crianças (gatos, cachorros, galinhas, porcos) e os animais de médio ou grande porte, utilizados ou não como instrumentos de trabalho pelos adultos e cujos nomes são atribuídos e conhecidos mais por estes (jumentos, cavalos, vacas, bois). 
16 Antonio Candido em Os parceiros do Rio Bonito chama a atenção para este fato ao afirmar que na educação sexual das crianças da família caipira paulista "meninos e meninas aprendem o essencial com os animais" (Cândido 2003: 49-50).

17 É comum no universo camponês que desde cedo as crianças tenham suas próprias fazendinhas, sendo donos de uma ninhada de pintinhos, uma cabra, um bezerrinho, ou qualquer outro filhote para dar início a sua própria criação, conforme observou Godoi: "Esta é constituída de um ou dois animais, de toda maneira de pelo menos uma fêmea, para que a criança possa começar a constituir seu próprio rebanho. As crianças, menino ou menina, desde muito pequenas são encorajadas a cuidar dos animais. O "pai de família" jamais se apropriará dos seus animais, somente em caso de necessidade - pois as necessidades da família prevalecem sobre a dos indivíduos - e, ainda nesses casos, essa apropriação toma a forma de empréstimo, que o pai tem a obrigação moral de restituir". (Godoi 2009: 298)..

18 Importante destacar que a expressão "estranhando" tanto pode ser utilizada para os bebês, que ao se verem num colo ou nos braços de alguém não-familiar desatam em choro, como para os animais que avançam ou acuam em direção ao estrangeiro.

19 Neste sentido, discordo da afirmação generalizada de Godoi de que "no sertão, mesmo se os cães são considerados animais domésticos, eles não são companheiros de brincadeira apreciados pelas crianças, como em outros lugares: este papel é dado aos cabritos" (Godoi 2009: 297). Entre os Capuxu o cachorro é um dos brinquedos favoritos das crianças. 


\section{REFERÊNCIAS BIBLIOGRÁFICAS}

CÂNDIDO, Antônio. 2003. "A vida familiar do caipira". In: Os Parceiros do Rio Bonito: estudo sobre o caipira paulista e a transformação dos seus meios de vida. $10^{\mathrm{a}}$ ed. São Paulo: Editora 34.

CODONHO, Camila. 2009. “Entre brincadeiras e hostilidades: percepção, construção e vivência das regras de organização social entre as crianças indígenas Galibi-Marworno". Revista Tellus 9 17: 137-161.

DAMATTA, Roberto. 1976. Um Mundo Dividido: A Estrutura Social dos índios Apinayé. Petrópolis: Vozes.

ELIAS, Norbert; SCOTSON, John. 2000. Os estabelecidos e os outsiders: sociologia das relações de poder a partir de uma pequena comunidade. Rio de Janeiro: Jorge Zahar Editor.

EVANS-PRITCHARD, Edward Evan. 2002. Os Nuer. São Paulo: Editora Perspectiva.

FREYRE, Gilberto. 2003 [1933]. Casa Grande \& Senzala: Formação da família brasileira sob o regime de economia patriarcal. $47^{\mathrm{a}}$ ed. São Paulo: Global Editora.

GEERTZ, Clifford. 1989 [1973]. A Interpretação das Culturas. Rio de Janeiro: Editora LTC.

GODOI, Emília Pietrafesa. 2009. "Reciprocidade e circulação de crianças entre camponeses do sertão”. In: E. Godoi; M. Menezes; R. Marin. (Orgs.) Diversidade do Campesinato: expressões e categorias, v. 2. São Paulo: UNESP/Brasília: Núcleo de Estudos Agrários e Desenvolvimento Rural.

HARRISON, Simon. 1990. Stealing People's Names: History and Politics in a Sepik River Cosmology. Cambridge/ Nova York : Cambridge University Press.

HUGH-JONES, Stephen. 2006. “The substance of Northweast Amazonian names". In: B Bodenhorn; G. Vom Bruck. The Anthropology of Names and Naming. Cambridge: Cambridge University Press.

LÉVI-STRAUSS, Claude. 2003. O Totemismo Hoje. Lisboa: Perspectiva do homem/Edições 70.

MAUSS, Marcel. 2003 [1969]. Sociologia e Antropologia. São Paulo: Cosac \& Naify.

MOURA, Margarida Maria. 2010. "Infância camponesa: legado dos nomes, dos bens antigos e das compras novas". Cadernos Ceru 21 (1):231 - 245.

NEEDHAM, Rodney. 1954. "The system of teknonyms and death-names of the Penan". Southwestern Journal of Anthropology 10: 416-431.

PINA CABRAL, João de. 1984. "Nicknames and the experience of community", Man 19 (1): 148-150.

2007. "Mães, pais e nomes no baixo sul (Bahia, Brasil)". In: J. Pina Cabral; S. Viegas (orgs.). Nomes: Género, Etnicidade e Família. Coimbra: Almedina.

RAMOS, Alcida. 2008. “Nomes Sanumá entre gritos e sussurros”. Etnográfica 12 (1): 59-69.

SILVA, Aracy Lopes da. 1986. Nomes e Amigos: Da Prática Xavante a uma Reflexão sobre os Jê. São Paulo, FFLCH, USP.

VIEGAS, Susana de Matos. 2008. “Pessoa e individuação: o poder dos nomes entre os Tupinambá de Olivença (sul da Bahia, Brasil) ". Etnográfica 12 (1): 71-94.

VIVEIROS DE CASTRO, Eduardo. 1986. Araweté: Os Deuses Canibais. Rio de Janeiro: Jorge Zahar Editores.

WOORTMANN, Ellen F. 1995. Herdeiros, parentes e compadres. São Paulo/Brasília: Hucitec/EdUnb. 


\section{RESUMO}

Neste artigo me dedico à análise do sistema de nominação Capuxu e sua importância para a constituição da pessoa, à extensão deste sistema para os animais como revelador das relações que o grupo estabelece com estes e ao sentido dos apelidos, atribuídos pelas crianças. Entre este povo camponês endogâmico do sertão da Paraíba descobri um sistema endonímico, que aliou a transmissão de nomes próprios a um curto leque de possibilidades de sobrenomes, prevalecendo quatro deles para praticamente duzentos habitantes. Este sistema foi paulatinamente substituído por um exonímico. Ainda assim, como esta transformação é recente, para resolver a confusão de nomes e sobrenomes semelhantes, a comunidade elegeu os apelidos, atribuídos pelas crianças e desde a infância, como designadores principais da pessoa. As crianças também exercem um importante papel na onomástica dos animais diluindo as fronteiras entre pessoas e bichos, revelando que há algo nestes que nos remete àquelas.

PALAVRAS-CHAVE: Onomástica; Capuxu; Apelidos; Pessoa; Animais.

\section{Naming is bringing into existence: onomastics (of children and animals) and nicknames in the production of the Capuxu person}

\section{ABSTRACT}

In this article, I analyse the Capuxu naming system and its importance to the constitution of personhood, as well as how this system is extended to animals as a revealing aspect of the relationships the group establishes with them. I also focus on meaning of nicknames assigned by children. Among this endogamous peasant people from the hinterland of Paraíba State, I have discovered a case of endonymy that combines name transmission with a short range of surname possibilities, with only four prevailing surnames for about two hundred inhabitants. This system was gradually replaced with exonymy. Since this transformation is relatively recent, in order to solve any eventual confusion between similar names and surnames, the community has chosen the nicknames assigned by children as the main designators of a person. Children also play an important role in onomastics of animals, diluting boundaries between people and animals, and revealing the existence of something in animals which relates to humans.

KEYWORDS: Onomastics; Capuxu; Nicknames; Person; Animals. 